\section{Coifst} Surgery, The Second Affiliated Hospital, Jiaxing University, Jiaxing, Zhejiang, China ${ }^{2}$ Department of Nuclear Medicine, Changhai Hospital, Second Military Medical University, Shanghai, China ${ }^{3}$ Department of Cardiothoracic Surgery, Zhejiang Provincial People's Hospital, Hangzhou, China

${ }^{4}$ Department of Pathology, Shuguang Hospital, Shanghai University of Traditional Chinese Medicine, Shanghai, China

\section{Correspondence to}

Dr Jun Zhang, Department of Cardiothoracic Surgery, The Second Affiliated Hospital, Jiaxing University, Jiaxing 314000, China;

18967383559@189.cn

Received 26 October 2018 Revised 22 November 2018 Accepted 26 November 2018 Published Online First 15 December 2018

D Check for updates

(C) Author(s) (or their employer(s)) 2019. No commercial re-use. See rights and permissions. Published by BMJ.

To cite: Zhang J, Dong A, Cui $Y$, et al. Thorax

2019:74:208-209.

\title{
Diffuse cavitary benign metastasising leiomyoma of the lung
}

\author{
Jun Zhang, ${ }_{1}^{1}$ Aisheng Dong, ${ }^{2}$ Yong Cui, ${ }^{3}$ Yang Wang, ${ }_{1}^{4}$ Jia Chen ${ }^{4}$
}

A 49-year-old woman presented to the pulmonary outpatient clinic with a 4-year history of cough and dyspnoea. Physical examination showed bilateral coarse breath sounds. Pulmonary function tests showed mixed ventilatory defects and small airway obstruction. Chest CT (figure 1) revealed diffuse pulmonary nodules smaller than $1 \mathrm{~cm}$ with cavitation. Pelvic ultrasonography revealed a uterine leiomyoma measuring $4 \times 3 \mathrm{~cm}$. A video-assisted thoracoscopic surgery wedge biopsy of the left lingular segment was performed. Microscopic examination revealed the nodules were composed of cytologically benign spindle cells without atypia (figure 2A,B). These spindle cells were positive for alpha-smooth muscle actin (figure 2C), oestrogen (figure 2D) and progesterone (figure 2E) receptor, and negative for D2-40, Human Melanoma Black-45 and S-100. In the nodules, there were entrapped tubular and cleft-like spaces lined by epithelial elements of the lung tissue (figure 2B), which were positive for thyroid transcription factor 1 (figure $2 \mathrm{~F}$ ). The clinical and histopathological findings were consistent with benign metastasising leiomyoma from uterine leiomyoma. The patient received 1 year of herbal therapy. Her cough and dyspnoea persisted. Follow-up chest CT and pelvic MRI performed 30 months after the biopsy showed enlargement of the pulmonary nodules and the uterine leiomyoma. Hormonal therapy with tamoxifen was started. The patient was still in follow-up.

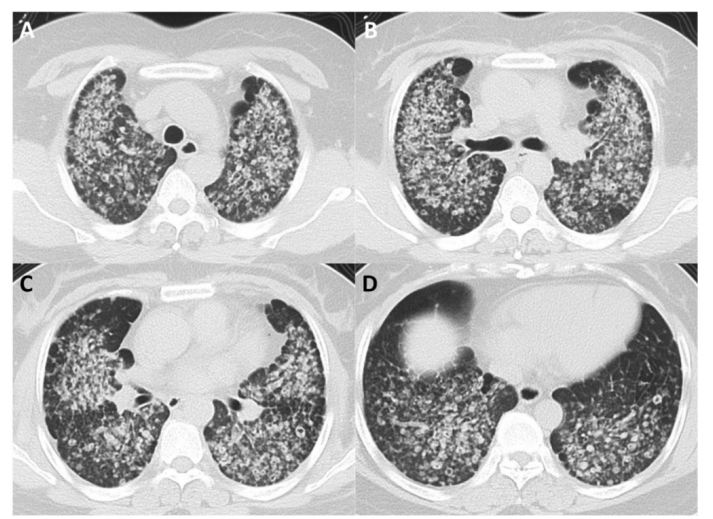

Figure 1 (A-D) Chest CT at different levels of the thorax showed diffuse pulmonary nodules ranging from a few millimetres to $1 \mathrm{~cm}$. The majority of the nodules had cavitation.

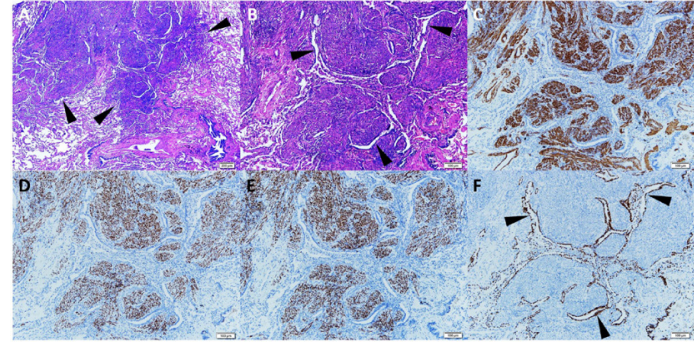

Figure 2 (A) Microphotograph of the biopsy specimen showed tumour nodules (arrowheads) with irregular margins (H\&E stain, original magnification $\times 40$ ). (B) The tumour nodule was composed of benign pink spindle cells with entrapped epithelial elements (arrowheads) of the lung tissue (H\&E stain, original magnification $\times 100$ ). (C-E) The tumour cells were positive for alpha-smooth muscle actin (C, original magnification $\times 100)$, oestrogen $(D$, original magnification $\times 100)$ and progesterone receptor $(E$, original magnification $\times 100)$ staining. $(F)$ The entrapped epithelial elements (arrowheads) of lung tissue were positive for thyroid transcription factor 1 staining (original magnification $\times 100$ ).

Pulmonary benign metastasising leiomyoma is a rare neoplastic process in which leiomyomas of the uterus metastasise to the lung. It usually occurs in women with a history of surgery for benign uterine leiomyoma. ${ }^{1}$ Radiologically, well-defined solitary or multiple pulmonary nodules ranging in size from a few millimetres to several centimetres are typical findings. ${ }^{1}$ Rare radiographic findings include cystic lesions, cavitary formation and military pattern. ${ }^{2}$ This case presenting as diffuse cavitary small nodules of the lungs is very unusual. The spindle cell infiltrates of distal airways or alveolar septa may lead to airway narrowing, air trapping and formation of cavity. This case indicates benign metastasising leiomyoma of the lung can present as diffuse micronodularity and macronodularity with some cavitation on CT, which may be mistaken for pulmonary tuberculosis or advanced cystic metastatic carcinoma. ${ }^{3}$

Contributors JZ initiated the idea for case reporting and prepared the final copy of the manuscript. AD took responsibility for reviewing the CT, chest radiograph and MRI. YC supervised and reviewed the final manuscript. YW and JC took responsibility for reviewing the histopathology. All authors have read and approved the final manuscript.

Competing interests None declared.

Patient consent for publication Obtained.

Ethics approval Ethics Committee of The Second Affiliated Hospital of Jiaxing University. 
Provenance and peer review Not commissioned; externally peer reviewed.

\section{REFERENCES}

1 Abramson S, Gilkeson RC, Goldstein JD, et al. Benign metastasizing leiomyoma: clinical, imaging, and pathologic correlation. AJR Am J Roentgenol 2001;176:1409-13.
2 Aboualfa K, Calandriello L, Dusmet M, et al. Benign metastasizing leiomyoma presenting as cystic lung disease: a diagnostic pitfall. Histopathology 2011;59:796-9.

3 Choe YH, Jeon SY, Lee YC, et al. Benign metastasizing leiomyoma presenting as multiple cystic pulmonary nodules: a case report. BMC Womens Health 2017; 17:81. 